\title{
Eosinophilic gastroenteritis in a patient with Ehlers-Danlos syndrome - A rare combination
}

\author{
I AL-TRAIF, MRCP(UK), L JEWELL, MD, FRCPC, ABR THOMSON, MD, PHD, FRCPC, FACP
}

I AL-TrAIF, L JEWELl, ABR THOMSON. Eosinophilic gastroenteritis in a patient with Ehlers-Danlos syndrome - A rare combination. Can J Gastroenterol 1992;6(3):129-132. A case of eosinophilic gastroenteritis in a patient with Ehlers-Danlos syndrome who presented with abdominal pain, vomiting, diarrhea and profound weight loss is presented. Because of inability to tolerate glucocorticosteroids, symptoms were treated with sodium chromoglycate and an elemental diet given by jejunostomy. The patient did well on this program. The gastrointestinal manifestations of eosinophilic gastroenteritis and Ehlers-Danlos syndrome are reviewed as well as the treatment modalities available for eosinophilic gastroenteritis.

Key Words: Ehlers-Danlos syndrome, Eosinophilic gastroenteritis

\section{Gastro-entérite a éosinophiles chez une patiente porteuse du} syndrome d'Ehlers-Danlos: une association rare

RÉSUMÉ: Cas de gastro-entérite à éosinophiles chez une patiente porteuse du syndrome d'Ehlers-Danlos qui présente des douleurs abdominales, des vomissements de la diarrhée et une perte de poids importante. À cause d'une intolérance aux glucocorticostéroïdes, les symptômes sont traités avec du chromoglycate de sodium et une alimentation élémentaire est administrée par jéjunostomie. La patiente a bien répondu au traitement. Les manifestations gastrointestinales de la gastro-entérite à éosinophiles et du syndrome d'Ehlers-Danlos sont passées en revue, de même que les modalités thérapeutiques disponibles dans les cas de gastro-entérite à éosinophiles.

Department of Medicine, Divisions of Gastroenterology and Pathology, University of Alberta - Walter Mackenzie Health Science Centre, University of Alberta, Edmonton, Alberta

Correspondence and reprints: Dr ABR Thomson, 519 Robert Newton Research Building, University of Alberta, Edmonton, Alberta T6C 2C2. Telephone (403) 492-6490, Fax (403) $492-7964$

Received for publication December 12, 1991. Accepted May 12, 1992
E OSINOPHILIC GASTROENTERITIS IS a rare disorder. Patients with this condition are probably underdiagnosed or misdiagnosed as having irritable bowel syndrome, particularly when the disease involves the serosal layer of the small bowel. The diagnosis often is made at surgery and is confirmed by serosal biopsy, although it may also be made by mucosal biopsy when that site is affected. A history of allergy is common, and the standard treatment of choice appears to be glucocorticosteroids. Ehlers-Danlos syndrome also rarely affects the gastrointestinal tract. The case of a young woman with both eosinophilic gastroenteritis and EhlersDanlos syndrome is discussed.

\section{CASE PRESENTATION}

A 33-year-old female was diagnosed at the Mayo Clinic, Rochester Minnesota, as having Ehlers-Danlos syndrome type VIII when she presented with a history for several months of epigastric pain and vomiting. She was treated with glucocorticosteroids. This was followed by a dramatic loss of muscle power, which reverted to normal after discontinuation of the drug. 


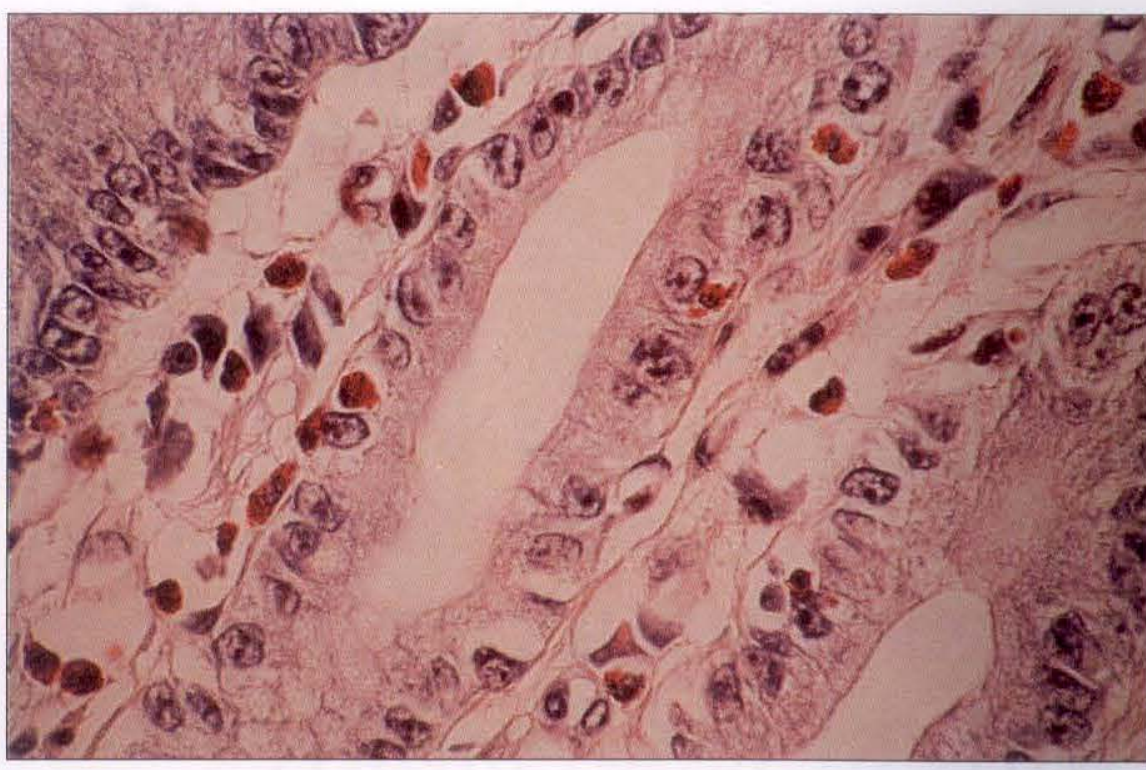

Figure 1) Eosinophils are present in the small intestinal lamina propria and infiltrate the epithelium (Luna's stain X160)

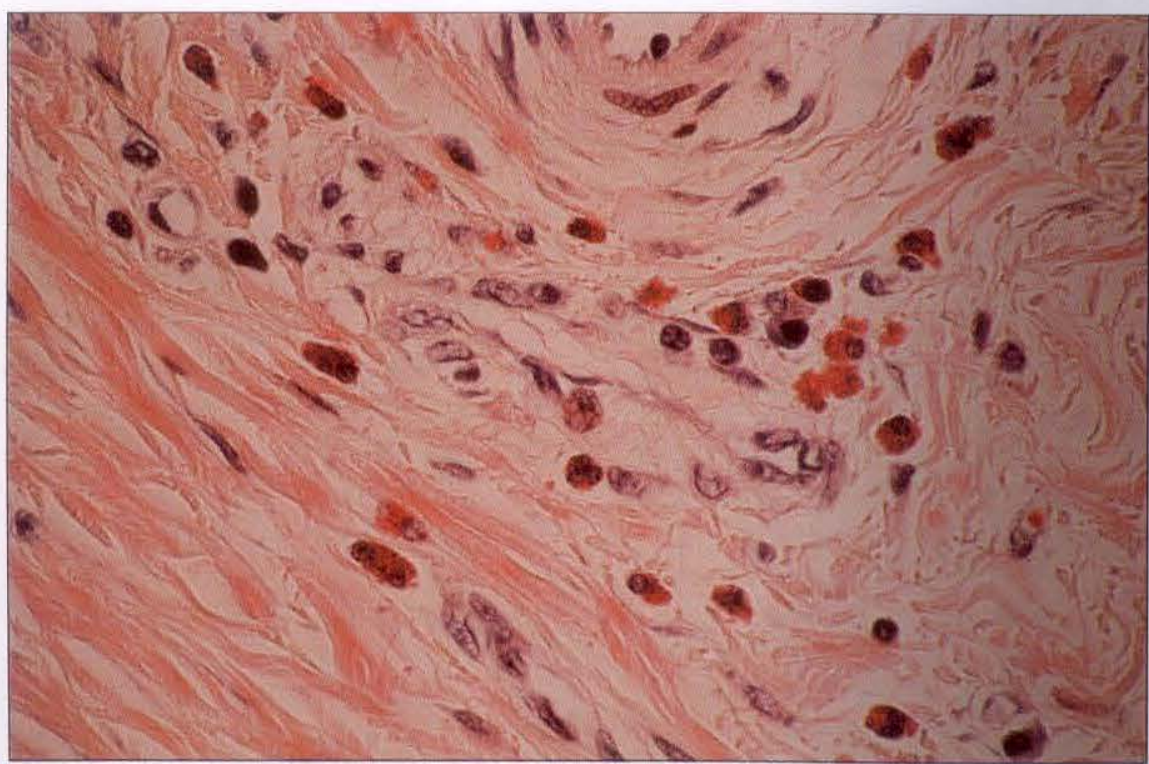

Figure 2) Large numbers of eosinophils are present in the submucosa of the small bowel (Luna's stain $\times 160$ )

The patient continued to be symptomatic with epigastric pain, vomiting and nonbloody diarrhea and she lost 16 $\mathrm{kg}$ body weight in two years. The patient had no known food allergies, and a good appetite. She had over 100 suspected drug allergies, ranging in severity from skin rash to near fatal anaphylactic shock which she had suffered twice in the past. Pertinent past medical history included duodenal ulcer disease for which antrectomy and vagotomy was performed; she currently denied symptoms suggestive of dumping syndrome.

The patient was adopted and her family history was not available. She has a 10-year-old daughter who also has Ehlers-Danlos syndrome.

Physical examination disclosed a thin young woman in no apparent distress, with normal vital signs. Abdominal examination revealed a midline scar from previous surgery, a tender epigastric region with no organomegaly and normal bowel sounds. Laboratory tests revealed hemoglobin of $12.2 \mathrm{~g} / \mathrm{dL}$, leukocyte count of $4800 / \mathrm{mm}^{3}$ with no eosinophilia and a normal platelet count of $250,000 / \mathrm{mm}^{3}$. The SMA-12 was normal. Stools were negative on several occasions for ova and parasites, culture and sensitivity, Clostridium difficile toxin and culture. Serum $\lg$ E level was slightly increased to 177 kunits/L, and vitamin E level was normal. Esophagogastroduodenoscopy revealed normal esophageal mucosa and a small gastric remnant with intense redness and prominent friable folds. Similar changes were present in the first and second part of the duodenum. There was no gastric outlet obstruction. Multiple biopsies from the duodenum revealed dense eosinophilic infiltrate into the lamina propria (Figure 1), compatible with eosinophilic gastroenteritis.

The patient was admitted to hospital to institute sodium chromoglycate treatment while under observation for any possible allergic reaction, as well as to institute a trial of an elemental diet. Sodium chromoglycate was given as a $100 \mathrm{mg}$ tablet test dose orally, which was tolerated well; this was subsequently advanced to $200 \mathrm{mg}$ orally qid. While in hospital, the patient had a J-tube placement and enteral diet feeding with Osmolite (Ross Laboratories). The patient was well when discharged on sodium chromoglycate, an antihistamine (diphenhydramine, Benadryl; Parke-Davis, $50 \mathrm{mg}$ qid) and multivitamins. She gained $5 \mathrm{~kg}$ of weight over the initial 10 week treatment period on Osmolite (three cans per day). Oral intake of food was slowly reintroduced, but the patient continued to use the elemental diet to supplement calorie, nitrogen and vitamin intake.

\section{DISCUSSION}

Eosinophilic gastroenteritis and Ehlers-Danlos syndrome are both rare disorders. In searching the literature, no reported association was found between the two disorders. They co-exist likely by chance alone. The present patient had no history of any of the gastrointestinal manifestations of Ehlers-Danlos syndrome described in 
the literature, such as multiple diverticula in the esophagus, stomach, colon and biliary tract (1), volvulus (2), infarction of the stomach (3), acute pancreatitis (4), colonic ectasia (5) (resulting in intractable constipation and spontaneous perforation) or hepatic artery-to-portal-vein fistula (6). Gastrointestinal symptoms probably resulted from eosinophilic gastroenteritis rather than the Ehlers-Danlos syndrome.

Eosinophilic gastroenteritis can involve the gastrointestinal tract from the mouth to the anus, including the mucosa, muscle layer and/or subserosa. Its pathogenesis remains obscure, although the disease has been induced in rats by vitamin $\mathrm{E}$ and selenium deficiency (7). The present patient's blood vitamin $E$ level was normal. In most cases there is no apparent cause, but eosinophilic gastroenteritis has been reported in association with certain parasitic diseases such as Eustoma rotundatum, Trichuris trichiura and Ancylostoma caninum (8). Multiple stool cultures in the present patient were normal.

In a large series of 40 eosinophilic gastroenteritis patients reviewed at the Mayo Clinic, abdominal pain, nausea, vomiting, weight loss, bloating and diarrhea were the most common symptoms (9). The present patient suffered the symptoms of pain and vomiting. Less common manifestations in-

ACKNOWLEDGEMENTS: The authors thank Mrs Doris Kurtz for secretarial assistance.

\section{REFERENCES}

1. Toyohara T, Kaneko T, Arakih T, Takahashi K, Nakamura T. Giant epiphrenic diverticulum in a body with Ehlers-Danlos syndrome. Pediatr Radiol 1989-90:437.

2. Iwama T, Sato H, Matsuzaki T, Mitaka S, Deguschi K, Mishima Y. EhlersDanlos syndrome complicated by eventration of the diaphragm, colonic perforation and jejunal perforation A case report. J Surg 1989;19:376-80.

3. Leung AK. Ehlers-Danlos syndrome with infarction of the stomach. J Roy Soc Med 1989;82:123. (Lett) clude dysphagia secondary to mucosal eosinophilic infiltrations of the esophagus, impaired growth in children presumably secondary to malabsorption and protein-losing enteropathy, pyloric outlet obstruction (10), repeated bowel obstruction with perforation requiring multiple surgical resection (11), massive eosinophilic ascites due to serosal involvement, biliary and duodenal obstruction (12), and small bowel perforation (13).

Eosinophilic gastroenteritis can be diagnosed by eosinophilic infiltrate in the bowel wall (Figure 2). However, mucosal biopsies may sometimes fail to show eosinophilic infiltrate, as the disease can be patchy or involve only the deep layers. Hence, full thickness biopsies may be needed to confirm the diagnosis. The disease may involve any part of the gastrointestinal tract; the common sites are the duodenum and proximal jejunum, followed by the gastric antrum and body. The terminal ileum is an uncommon site of involvement. The present patient had had an antrectomy, but the jejunum was involved with eosinophilic gastroenteritis.

Some $30 \%$ of esinophilic gastroenteritis patients with mucosal disease have malabsorption and protein-losing enteropathy, and a history of allergy is seen in up to $80 \%$ of patients. Peripheral eosinophilia is found in $77 \%$ of cases, but was not seen in the current patient. Serum IgE level and erythro-

4. Sarr-Carbonell S, Jimenez SA. Ehlers-Danlos syndrome associated with acute pancreatitis. J Romantol 1989;16:1390-4.

5. Shi EC, Bohane TD, Bowring SC. Prophylactic colectomy in Ehlers-Danlos syndrome with colonic ectasia. J Pediatr Surg 1989;24:1187-8.

6. Can T, Razor M, Gmeinwieser J, Heuck A. The Ehlers-Danlos syndrome type 4 with an unusual combination of organ malformation. Cardiovasc Intervent Radiol 1988;11:288-91.

7. Hong CB, Chow CK. Induction of eosinophilic enteritis and eosinophilia in rats by vitamin $E$ and selenium deficiency. J Clin Gastroenterol 1988;48:182-92.

8. Prociv P, Croese J. Eosinophilic enteritis caused by dog hook worm Ancylostoma canium. Lancet cyte sedimentation rate may be elevated. The present patient had slightly increased $\operatorname{lgE}$ levels, and suffered from multiple allergies. The most common finding on barium examination is thickening and/or irregularity of the mucosal folds in the stomach and/or small intestine (14). Recent barium studies were not available for this patient.

The standard treatment of eosinophilic gastroenteritis is glucocorticosteroid therapy, but this was not tolerated by the present patient. Other treatment modalities include elemental diet, but relapse is common $(15-17)$. While on Osmolite first by J-tube and then by mouth, the patient did well, gaining $5 \mathrm{~kg}$ in 10 weeks. Sodium chromoglycate has been shown to prevent release of toxic mediators such as serotonin and histamine from mast cell membranes. It has been successfully used in the treatment of allergic conditions such as asthma, milk allergy gastrointestinal allergy in adults (18) and malabsorption secondary to systemic mastocytosis (19). Unfortunately, there are no double-blind controlled trials for evaluation of the benefit of any of the above treatment modalities in eosinophilic gastroenteritis. Sodium chromoglycate has been successful in several case reports of eosinophilic gastroenteritis $(20,21)$. It appeared to be useful in this patient when combined with an elemental diet.

1990;335:1299-302.

9. Talley NJ, Shorter RJ, Phillips SF, Zinsmpistar AR. Eosinophilic gastroenteritis: Clinical pathological study of patients with disease of the mucosa muscle layer and subserosa tissue. Gut 1990;31:154-8.

10. Dodge JA. Pyloric stenosis and eosinophilic gastroenteritis in infants. J Pediatr Gastroenterol Nutr 1988;7:301-2. (Lett)

11. Hsueh CS, Shih LY, Chen M. Repeated bowel resection for eosinopilic gastroenteritis with obstruction and perforation. Case report. Acta Chir Scand 1990;156:333-6.

12. Frahvash MJ, Bustani B, Frahvash MR, Rivanlou G. Eosinophilic gastroenteritis presenting with biliary and partial duodenal obstruction. J Gastroenterol 1990;85:1022-4. 
13. Lysey J, Eida I, Schugar L. Eosinophilic gastroenteritis with small bowel perforation. J Clin Gastroenterol 1986;8:694-5. (Lett)

14. MacCarty RL, Talley NJ. Barium studies in diffuse eosinophilic gastroenteritis. Gastrointest Radiol 1990;15:183-7.

15. Klein NC, Hargrove RL, Sleisenger $\mathrm{MH}$, Jeffries $\mathrm{GH}$. Eosinophilic gastroenteritis. Medicine 1970;49:299-319.

16. Leinbach GE, Rubin CE. Eosinophilic gastroenteritis: A simple reaction to food allergies? Gastroenterology 1970;59:874-89.

17. Heatley R, Harris V, Atkinson AP. Treatment of a patient with clinical features of both eosinophilic gastroenteritis and polyarteritis nodosa with oral sodium chromoglycate. Dig Dis Sci 1980;25:470-6.

18. Kingsley PJ. Oral sodium chromoglycate in gastrointestinal allergy. Lancet 1974;ii:1011.

19. Dolovich J, Punthakee ND, MacMillan AB, Obsbaldesten GJ.
Systemic mastocytosis: Control of lifelong diarrhea by ingested disodium chromoglycate. Can Med Assoc J 1974;111:684.

20. Moots RJ, Prouse P, Gumpel JM. Near fatal eosinophilic gastroenteritis responding to oral sodium chromoglycate. Gut 1988;29:1282-5.

21. Di-Gioacchino M, Pizzicannela G, Fini $\mathrm{N}$, et al. Sodium chromoglycate in the treatment of eosinophilic gastroenteritis allergy. Allergy 1990;45:161-6.1 


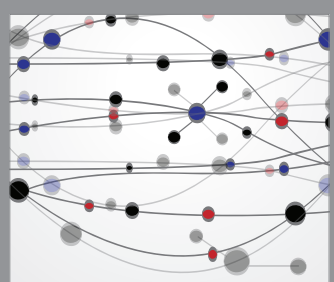

The Scientific World Journal
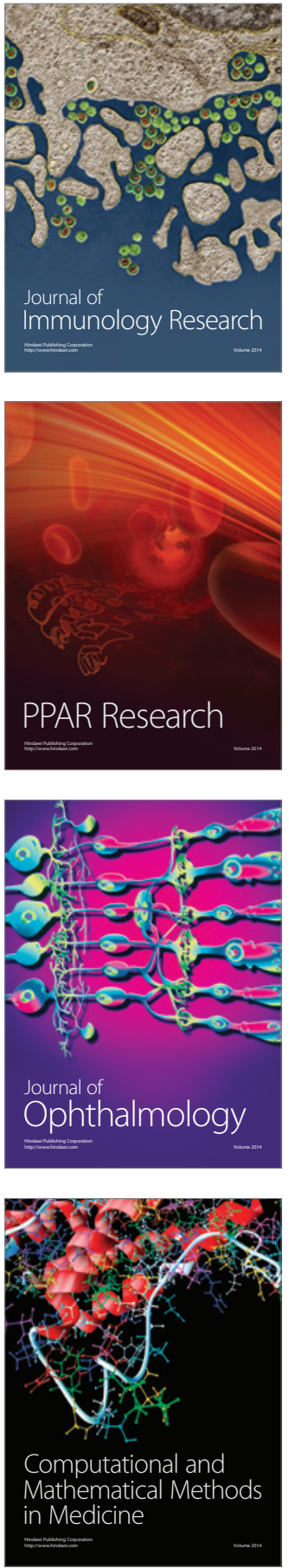

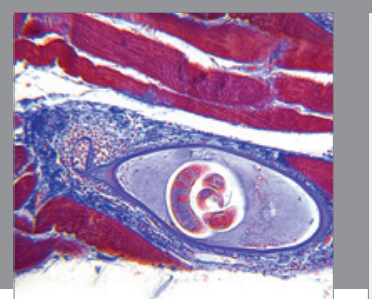

Gastroenterology Research and Practice

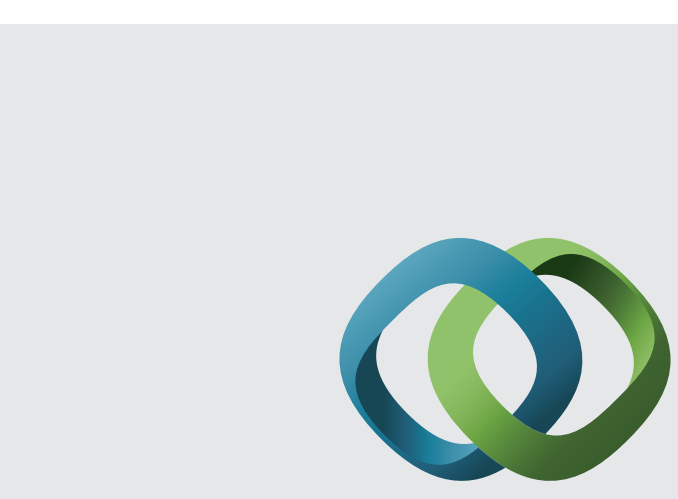

\section{Hindawi}

Submit your manuscripts at

http://www.hindawi.com
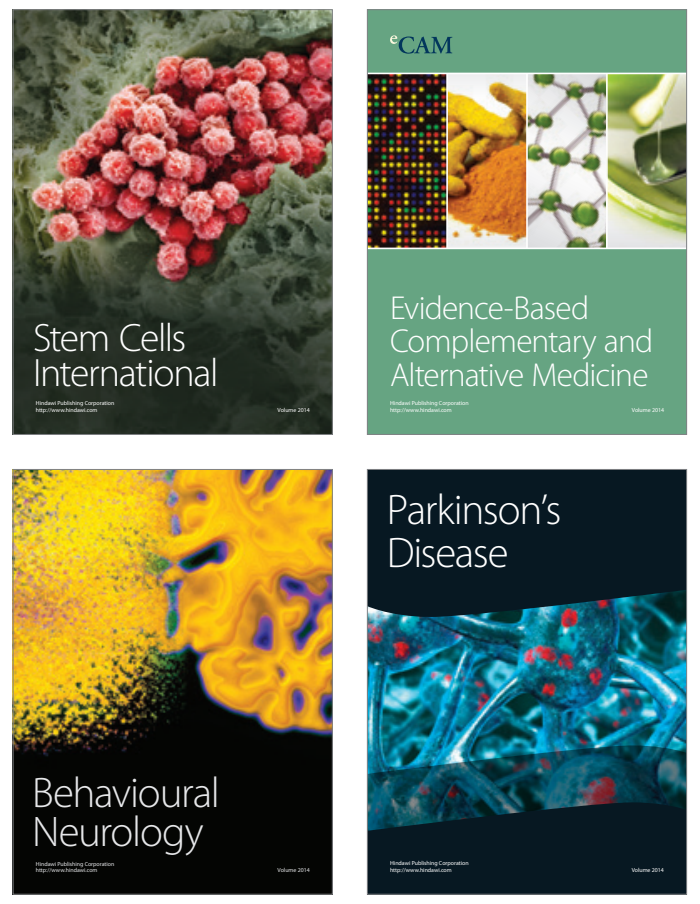
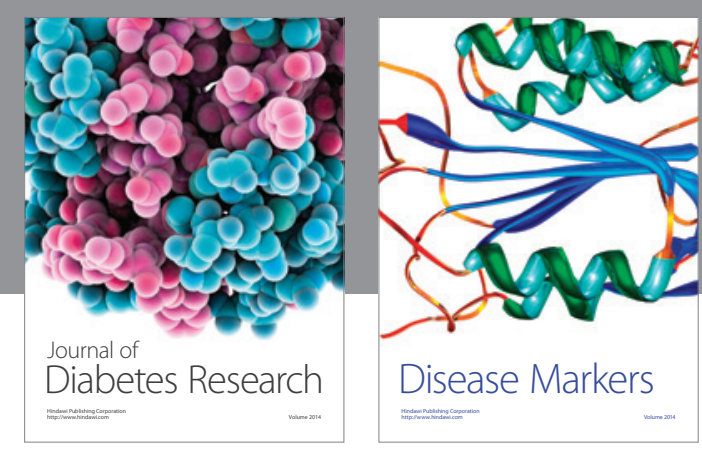

Disease Markers
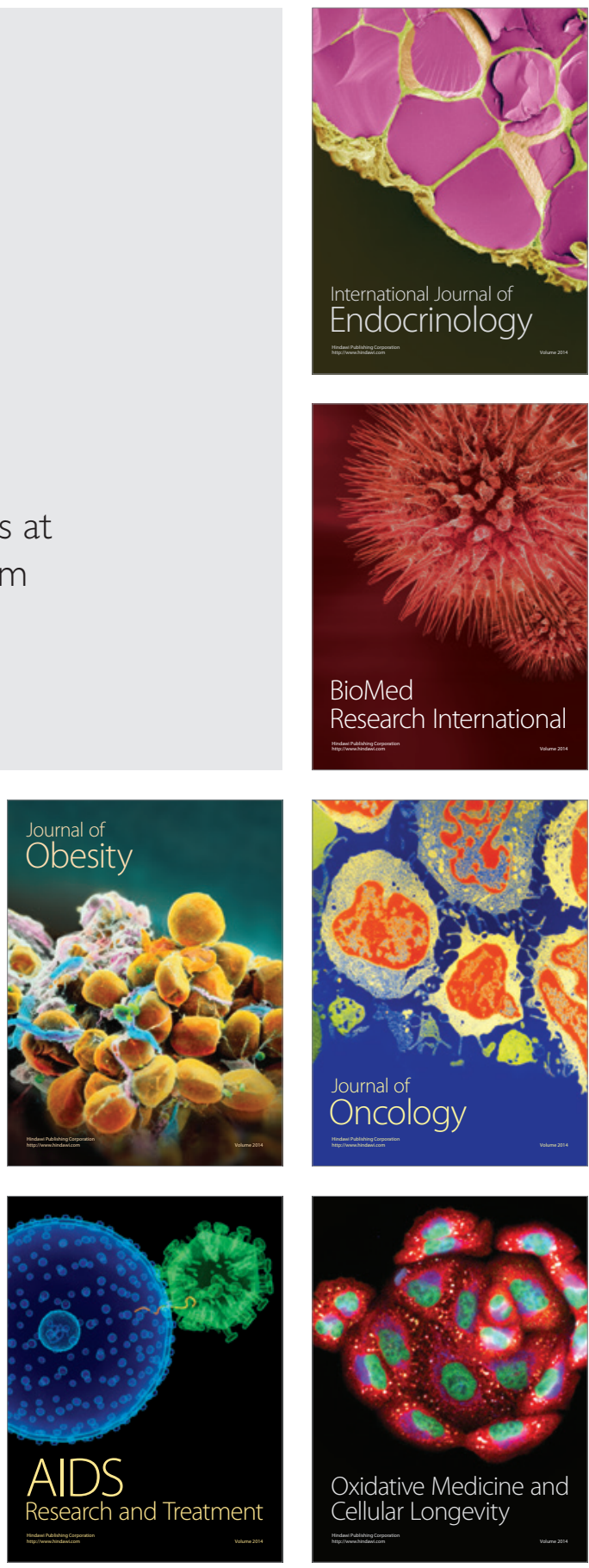